\title{
Small-Diameter Magnetic and Metallic Nanowire Arrays Grown in Anodic Porous Alumina Templates Anodized in Selenic Acid
}

Mahdieh Ahmadzadeh

University of Kashan

Mohammad Almasi Kashi ( $\sim$ almac@kashanu.ac.ir)

University of Kashan https://orcid.org/0000-0002-2742-3797

Mohammad Noormohammadi

University of Kashan

Abdolali Ramazani

University of Kashan

Research Article

Keywords: Magnetic nanowires, metallic nanowires, pore filling, selenic acid, pulsed electrodeposition

Posted Date: February 10th, 2021

DOI: https://doi.org/10.21203/rs.3.rs-172696/v1

License: (c) (i) This work is licensed under a Creative Commons Attribution 4.0 International License.

Read Full License 


\title{
Small-diameter magnetic and metallic nanowire arrays grown in anodic porous alumina templates anodized in selenic acid
}

\author{
M. Ahmadzadeh ${ }^{1}$, M. Almasi Kashi ${ }^{1,2^{*}}$, M. Noormohammadi ${ }^{1}$, A. Ramazani ${ }^{1,2}$ \\ ${ }^{1}$ Department of Physics, University of Kashan, Kashan 87317-51167, Iran \\ ${ }^{2}$ Institute of Nanoscience and Nanotechnology, University of Kashan, Kashan 87317-51167, Iran \\ *E-mail: almac@kashanu.ac.ir; Phone/Fax: +98 3155912578
}

\begin{abstract}
Despite the introduction of selenic acid for anodic porous alumina (APA) preparation with small nanopore diameters $(<20 \mathrm{~nm})$, no attempt has been made to use it in the fabrication of small-diameter magnetic and metallic nanowire arrays. In this paper, considering the high cost of selenic acid, it has been attempted to initially use oxalic acid in preparation of an ordered pattern in the first anodization step, and then employ selenic acid for the second anodization step by matching the appropriate voltage. By investigating the nanopore formation pattern in both acids, it was shown that the nanopores formed in the selenic acid had considerably smaller diameter $(13 \mathrm{~nm})$ than that of oxalic acid (35 $\mathrm{nm})$. Under optimized conditions of electrodeposition, various metals were then grown in the selenic APA templates in order to fabricate nanowires with small diameters. The pore filling percentage and crystalline properties were also investigated.
\end{abstract}

\section{Keywords}

Magnetic nanowires, metallic nanowires, pore filling, selenic acid, pulsed electrodeposition.

\section{Abbreviations}

Anodic porous alumina (APA); pulsed electrodeposition (PED); field-emission scanning electron microscopy $(\mathrm{FESEM})$; pore filling percentage $\left(F_{\rho}\right)$; vibrating sample magnetometer $(\mathrm{VSM})$. 


\section{Introduction}

The fabrication method of nanostructures and nanomaterials such as nanorods, nanowires, nanotubes, and nanodots based on the template is a combination technique, employing different metals, semiconductors and oxides [1-3]. The templates used for the fabrication of these nanostructures include anodic porous alumina (APA) [4], porous silicon template [5], carbon nanotubes [6], polymeric membranes [7] etc., among which the APA template has been mostly used in the preparation of nanotubes and nanowires. Controlling structural properties of APA has been of great practical importance for use in a variety of conventional and sophisticated materials and applications such as templates, filters, magnetic storage media, three-dimensional photonic crystals, plasmonic nanodevices, and thermal resistors [8-11]. Electrochemical methods have been more commonly used compared to chemical ones because the chemical growth of APAs is uncontrollable and difficult. APA templates are fabricated by anodizing aluminum (Al) in several acidic electrolytes so that their nanostructural characteristics can be tailored by appropriate selection of the electrolyte and anodization voltage [1214]. In this regard, three electrolyte types have been used for anodizing $\mathrm{Al}$ under various applied voltages, resulting in the following self-ordered APAs: sulfuric acid (19-27 V), oxalic acid (40 V), and phosphoric acid (160-195 V). Accordingly, the interpore distance of APAs can be tuned based on the applied voltage, arising from a proportional constant $(\mathrm{k})$ of $2.5 \mathrm{~nm} / \mathrm{V}$. The aforementioned anodization electrolytes have also been employed for the surface finishing of $\mathrm{Al}$ and its alloy compounds, thus enhancing their chemical and physical properties [15] while also being used for self-ordered fabrication of APAs [16].

On the other hand, malonic and tartaric acids have been investigated for preparing APAs, giving rise to self-ordered templates at $120 \mathrm{~V}$ and $195 \mathrm{~V}$, respectively. A part from the five acidic electrolytes in the anodization of $\mathrm{Al}$, other solutions such as citric, glycolic, chromic and malic acids have been 
used, according to the literature [17-19]. Moreover, mixing the electrolyte solutions with each other has offered the opportunity of controlling the anodization voltage and respective cell size [20-26].

In recent years, $\mathrm{Al}$ anodization has been newly reported using selenic acid electrolyte $\left(\mathrm{H}_{2} \mathrm{SeO}_{4}\right)$ [27-30]. As known, the solution of selenic acid can dissolve some metals including silver, gold and palladium. The standard electrode potentials for selenic acid are as follows:

$$
\begin{array}{lrl}
\mathrm{SeO}_{4}{ }^{2-}+4 \mathrm{H}^{+}+2 e^{-}=\mathrm{H}_{2} \mathrm{SeO}_{3}+\mathrm{H}_{2} \mathrm{O} & E^{0}=1.151 \mathrm{~V} \\
\mathrm{H}_{2} \mathrm{SeO}_{3}+4 \mathrm{H}^{+}+4 e^{-}=\mathrm{Se}+3 \mathrm{H}_{2} \mathrm{O} & E^{0}=0.739 \mathrm{~V}
\end{array}
$$

It is worth noting that, while the cell size of the APA template induced in selenic acid based electrolyte is similar to the cell size of the oxalic APA, its pore diameter is smaller, being similar to the APA pore diameter formed in sulfuric acid. In other words, the APA formed in selenic acid can be used as a substitute for the oxalic APA, thus preparing small-diameter templates. APAs formed in carboxylic acids including oxalic acid are fluorescent [31,32], thereby complicating the corresponding applications as a matrix for spectroscopic research (e.g., Raman spectroscopy) [33]. In spite of the templates fabricated using oxalic and phosphoric acids, the APAs formed in selenic acid do not show fluorescence background in the Raman spectra [34].

As a starter material, one of the important applications of APAs is to fabricate nanowire arrays, arising from their high-ordering, controllable diameter and length of the pores, and significant mechanical and chemical properties [35]. In this respect, although selenic APAs have already been fabricated, no attention has been paid to the fabrication of nanowires inside their nanopores.

The electrodeposition process of nanowires inside APA templates includes three well-known methods: direct current, alternating current and pulsed electrodeposition (PED) [36]. Prior to performing the direct current method, the alumina barrier layer must be removed, and a conductive 
layer is sputtered at the bottom of nanopores to act as the cathode. Such further processing is not suitable for large-scale applications and fast fabrication of nanowires.

On the other hand, by thinning of the barrier layer in chemical solution, the alternating current method is performed [37], which in turn requires high voltage and frequency to be applied to deposit nanowires, resulting in low pore filling percentage $\left(F_{\rho}\right)$ of the APAs [38-39].

Using the PED method, one can overcome the aforementioned flaws in the direct and alternating current methods as it employs off time between deposition pulses, refreshing the concentration of metal ions at the electrodeposition interface, and increasing uniformity of the growth of nanowires [40-41]. In this way, the PED method may lead to the formation of uniform nanowires, although the pore filling and nanowire electrodeposition efficiency depend on a variety of factors such as the diameter and length of nanopores, electrolyte concentration, and so forth. Changing the nanopore diameter can influence some properties of nanopores and nanowires fabricated in them, including the variation of transparency and conductivity of metallic nanowires [8], the change in magnetic properties of magnetic nanowires [42], the variation of optical properties of nanopores [9], etc.

In this paper, APA templates prepared by selenic anodization are employed in the fabrication of small diameter $(13 \mathrm{~nm})$ nanowires with an inter-wire distance of $100 \mathrm{~nm}$. Due to the high cost of selenic acid, the two-step anodization process is performed with the combination of oxalic and selenic acids as the first and second steps, respectively. Using a PED method, the nanopores of APA are filled with different magnetic and metallic elements. Field-emission scanning electron microscopy (FESEM) analysis is used to determine $F_{\rho}$. Magnetic properties of the magnetic nanowires are measured by a vibrating sample magnetometer (VSM) at room temperature. The crystalline structure of nanowires is also studied by X-ray diffraction (XRD). 


\section{Experimental details}

High purity $\mathrm{Al}(99.999 \%)$ disk, $8 \mathrm{~mm}$ in diameter and $1 \mathrm{~mm}$ in thickness, was used to fabricate APA templates by using a two-step anodization process [43]. Prior to the anodization, the Al sheets were ultrasonically cleaned for $5 \mathrm{~min}$ in acetone. The samples were thoroughly washed with deionized water and then electropolished in a solution of perchloric acid and ethanol at a ratio of 1 to 4 at $0{ }^{\circ} \mathrm{C}$. For the electropolishing procedure, the current density and time were set to $100 \mathrm{~mA} / \mathrm{cm}^{2}$ and 10 min, respectively.

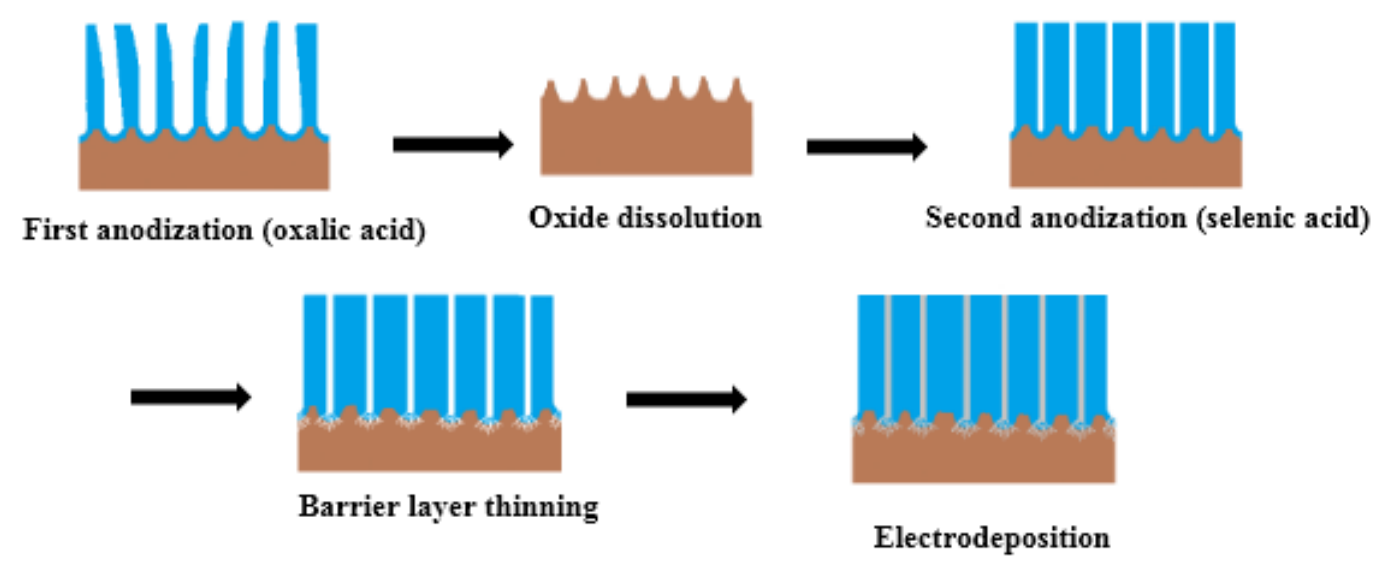

Figure 1: Schematic diagram of various steps of nanowire preparation.

Optimum conditions for selenic acid were considered for anodization according to reports on selenic acid [29]. But given the availability and interpore distance similar to those formed by oxalic acid, the first step of anodization was carried out using oxalic acid, and in the second step of anodization, the electrolyte solution was replaced by selenic acid. For this purpose, the first step of anodization proceed in oxalic acid at $40 \mathrm{~V}$ and $17^{\circ} \mathrm{C}$ and $5 \mathrm{~h}$. In order to remove the oxide layer formed in the first step, chemical wet etching was performed in $0.2 \mathrm{M}$ chromic and $0.5 \mathrm{M}$ phosphoric acid solutions at $60{ }^{\circ} \mathrm{C}$ for $6 \mathrm{~h}[41,45]$. The second step of anodization was performed using selenic acid at $45 \mathrm{~V}$ and $0{ }^{\circ} \mathrm{C}$ for $4 \mathrm{~h}$. This process resulted in nanopore arrays with an approximate diameter and interpore distance of $13 \mathrm{~nm}$ and $100 \mathrm{~nm}$, respectively. To promote thinning of the barrier layer, following the second anodization, the voltage decreased stepwise from 45 to $12 \mathrm{~V}$ with a rate of 0.001 V/s. This process causes the formation of roots at the pore bottom, thereby facilitating the electrodeposition (see Fig. 1) [44]. 
The pulsed electrodeposition process was then performed, and the samples and graphite acted as working and counters electrodes, respectively. The pulsed electrodeposition process was carried out by a pulsed ac power supply (GW-Instek SFG-830) controlled by a programmable logger. The purpose of this study was to prepare small diameter nanowires, therefore, the pore filling of obtained nanoporous template in oxalic and selenic acids was examined using magnetic and metallic elements such as $\mathrm{Ni}$, $\mathrm{Co}, \mathrm{Zn}$, and $\mathrm{AgNi}$. To electrodeposit such a sample, the concentration of electrolyte solutions was set as follows:

Ni nanowire: $0.6 \mathrm{M} \mathrm{NiSO}_{4} \cdot 7 \mathrm{H}_{2} \mathrm{O}+0.72 \mathrm{M}$ boric acid,

Co nanowire: $0.3 \mathrm{M} \mathrm{CoSO} \cdot 7 \mathrm{H}_{2} \mathrm{O}+0.72 \mathrm{M}$ boric acid,

Zn nanowire: $0.6 \mathrm{M} \mathrm{ZnSO}_{4} \cdot 7 \mathrm{H}_{2} \mathrm{O}+0.72 \mathrm{M}$ boric acid, and

AgNi nanowire: $0.01 \mathrm{M} \mathrm{AgNO}_{3}+0.3 \mathrm{M} \mathrm{NiSO}_{4} \cdot 7 \mathrm{H}_{2} \mathrm{O}+0.72 \mathrm{M}$ boric acid.

It should be noted that, a bath of $0.15 \mathrm{M} \mathrm{CoSO}_{4} \cdot 7 \mathrm{H}_{2} \mathrm{O}, 0.9 \mathrm{M} \mathrm{NiSO}_{4} \cdot 7 \mathrm{H}_{2} \mathrm{O}, 0.15 \mathrm{M} \mathrm{FeSO}_{4} \cdot 5 \mathrm{H}_{2} \mathrm{O}$ with $45 \mathrm{~g} / \mathrm{l}$ boric acid at $5{ }^{\circ} \mathrm{C}$ was employed to fill the branched nanopores of the APA template (i.e. CoFeNi pre-plating) [45], prior to the electrodeposition of $\mathrm{Zn}$ nanowires. Other conditions for each element were set according to the optimal conditions reported previously [46].

Table 1. Electrodeposition conditions for preparing magnetic and metallic nanowires in selenic APA templates.

\begin{tabular}{|c|c|c|c|c|c|c|}
\hline $\begin{array}{c}\text { Nanowire } \\
\text { electrodeposition }\end{array}$ & $\mathbf{p H}$ & $\begin{array}{c}\text { Solution } \\
\mathbf{t i m e} \\
\mathbf{( m s})\end{array}$ & $\begin{array}{c}\text { Off } \\
\mathbf{t i m e} \\
(\mathbf{m s})\end{array}$ & $\begin{array}{c}\text { Reduction } \\
\text { voltage } \\
(\mathbf{V})\end{array}$ & $\begin{array}{c}\text { Oxidation } \\
\text { voltage } \\
(\mathbf{V})\end{array}$ & $\begin{array}{c}\text { Current density } \\
\left.\mathbf{( \mathbf { m } A} / \mathbf{c m}^{\mathbf{2}}\right)\end{array}$ \\
\hline $\mathrm{Ni}$ & 4 & 2.4 & 19.2 & 13 & 12 & 50 \\
\hline $\mathrm{Co}$ & 5.2 & 2.4 & 50 & 12 & 10 & 20 \\
\hline $\mathrm{Zn}$ & 4 & 2.4 & 19.2 & 13 & 12 & 20 \\
\hline $\mathrm{CoFeNi}$ pre-plating & 5 & 2.4 & 24 & 13 & 12 & 15 \\
\hline $\mathrm{AgNi}$ & 4 & 2.4 & 19.2 & 13 & 12 & 20 \\
\hline
\end{tabular}


The magnetic properties of the prepared nanowires were measured using a vibrating sample magnetometer (VSM, Magnetic DaneshPajoh Kashan Co.) at room temperature with an applied field parallel to the nanowire axis. Pore filling was then evaluated for the magnetic and metallic elements. To calculate the filling percentage $(\mathrm{F} \rho)$ theoretically, we first need to calculate the theoretical charge for full filling of the nanopores based on the following equation: [46, 47].

$Q_{\text {theo }}(C)=\frac{Z F \rho L S_{\text {eff }}}{m}$

where $Z$ is the valency of the deposited ion, $\mathrm{F}$ is the Faraday constant, $\rho$ is the density of the element, $m$ is the molecular weight of the element, and L is the thickness of the APA template. Also, $S_{e f f}$ can be obtained from the following equation:

$S_{e f f}=\pi\left(\frac{d}{2}\right)^{2} f S$

in which $d$ is the pore diameter, $f$ is the pore density in APA and $S$ is the sample surface area exposed to the electrolyte. Thus, the theoretical pore filling $\left(\mathrm{F}_{\rho}\right)$ is calculated from the following relation:

$\% F_{\rho}=\frac{Q_{\text {rev }}}{Q_{\text {theo }}} \times 100$

where $Q_{\text {rev }}$ is the electrical charge deposited for the nanowire growth up to the top surface of APA templates. Two methods are mentioned detecting the nanowire overflow process: the first method is reversal of the decreasing potential during electrodeposition and the noise generation in the potential profile. The other method is the change of the recorded electric charge slope (which varies for different elements).

The experimental pore filling was also obtained through FESEM (MIRA3 TESCAN operating at $15 \mathrm{kV}$ ) images of the top surface of the filled APA template using Image $\mathrm{J}$ program. The crystalline properties of magnetic and metallic nanowires were investigated by XRD (XRD; Philips, X'PertPro; Cu $\mathrm{K} \alpha$ radiation with $\lambda=0.154 \mathrm{~nm}$ ), after dissolving the residual aluminum from APA template in $\mathrm{CuCl}_{2}$ solution. 


\section{Results and discussion}

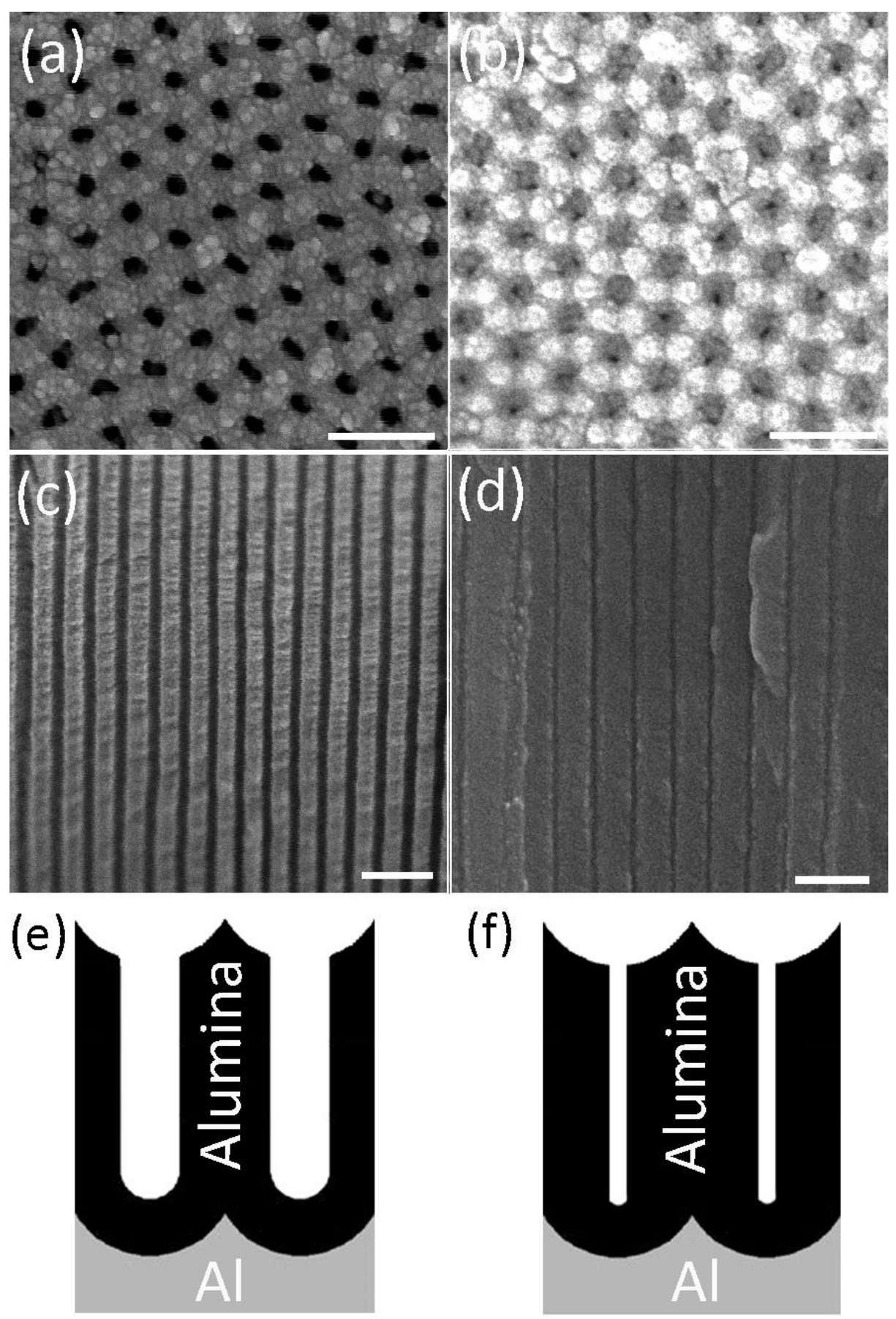

Figure 2: FESEM images of: (a) nanopores after the second anodization with oxalic acid, (b) nanopores after the second anodization with selenic acid, c) cross-section of the nanoporous template after the second anodization with oxalic acid, and d) cross-section of the nanoporous template after the second anodization with selenic acid. Schematic view of nanopores grown in alumina templates by using: (e) oxalic acid (larger diameter) and (f) selenic acid (smaller diameter). The scale bar in all parts is $200 \mathrm{~nm}$. 
Figure 2 shows FESEM images of alumina nanopores which have been fabricated during the second andization process in oxalic and selenic acids. The first anodization step of both samples has been performed in oxalic acid to form an ordered pattern on the Al substrate after dissolving the oxide layer. By considering the much lower price of oxalic acid than selenic acid, the ordered pattern was selected to be created by the oxalic acid. As can be seen in Figures $2 a$ and $2 b$, the diameters of nanopores formed in the second anodiazation step are different from each other. For the oxalic acid anodization, the average diameter of nanopores reaches $35 \mathrm{~nm}$, whereas the average diameter of nanopores reaches $13 \mathrm{~nm}$ for the selenic acid anodization. The diameter trends continue, according to Figures $2 \mathrm{c}$ and $2 \mathrm{~d}$. This indicates that the chemical dissolution occurring in the electrolyte/oxide interface is completely different from each other, so that it is concentrated in the pore centers using the selenic acid. This is perhaps the reasoning behind the different proportionality coefficient between the selenic anodization voltage and nanopore diameter $\left(K_{D}^{S e l}=0.24 \mathrm{~nm} / \mathrm{V}\right)$ compared to that of the reported values for the mild anodization $\left(K_{D}^{M A}=0.9 \mathrm{~nm} / \mathrm{V}\right)[48]$ and hard anodization $\left(K_{D}^{H A}=0.4 \mathrm{~nm} / \mathrm{V}\right)[49]$. For the anodization in selenic acid, while the passed current is in order of the mild anodization, the resulting nanopore diameter indicates that the dissolution in selenic acid follows a different process, leading to a small oxide dissolution surface. However, this process continues, although the patterned alumina layer has been obtained using the oxalic acid. In Figure 3, the total thickness and the barrier layer area has been shown. A layer with a thickness of $6 \mu \mathrm{m}$ is formed, and the pore diameter in the barrier layer interface shows that the oxide formed has continued its own regime of the oxide dissolution during the entire process so that the diameter remains small. 


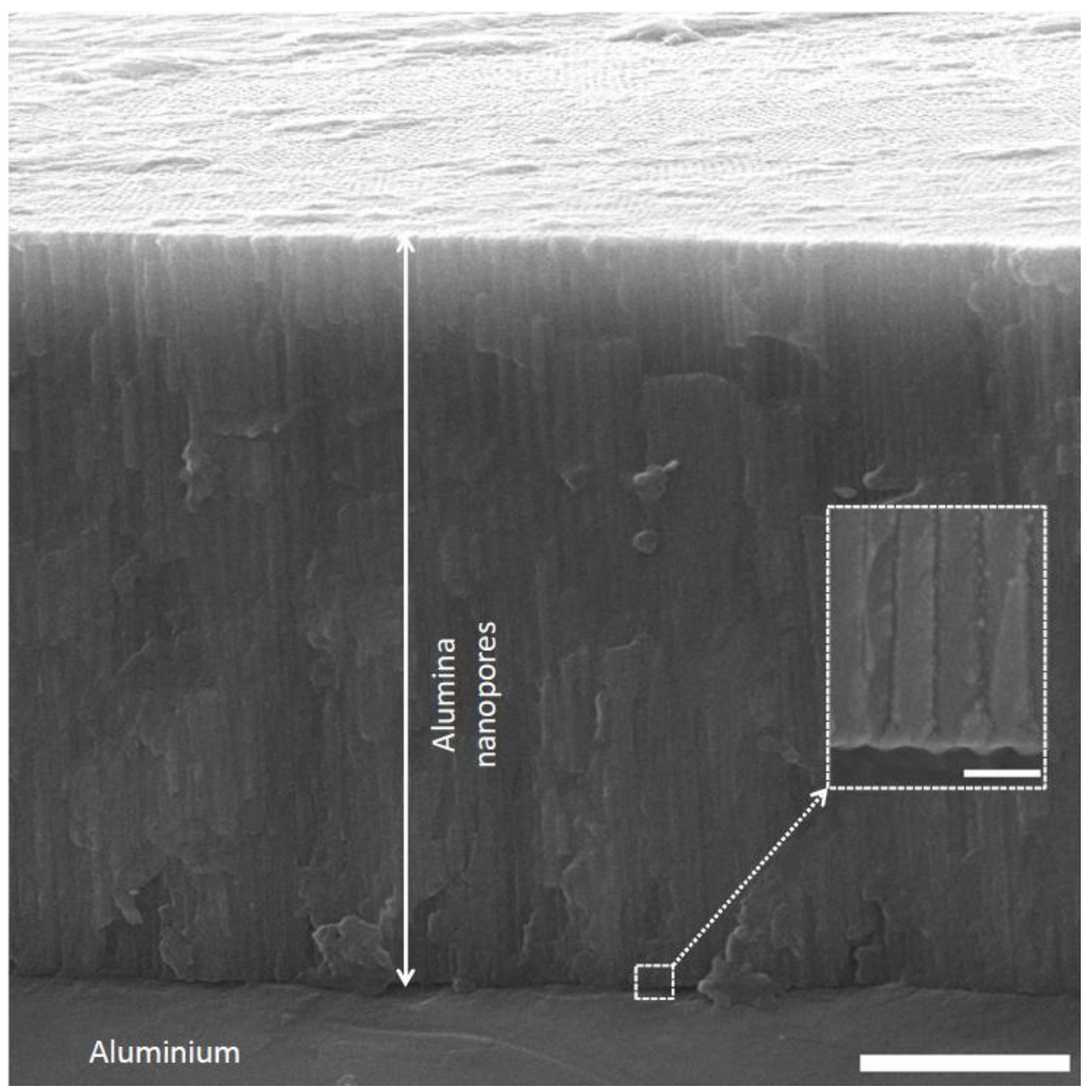

Figure 3: Cross-sectional FESEM image of alumina nanopores grown in selenic acid (the scale bar is $2 \mu \mathrm{m}$ ). The inset shows the barrier layer of the nanopores (the scale bar is $200 \mathrm{~nm}$ ).

According to the experimental details, the resulting templates were thinned in oxalic (Ox) and selenic (Se) acids, and subsequently filled with magnetic and metallic nanowires. As can be seen in Figure 4a, the thinning current for the Ox and Se samples is completely different from each other. Both samples have initially undergone the selenic anodization for 4 hours. Then, in the following, one of them has been thinned by the selenic acid and the other with the oxalic acid. The anodization current of the sample anodized with the selenic acid is averagely $0.3-0.4 \mathrm{~mA}$ higher, indicating higher electrical conductivity of this layer as the voltage of both samples has decreased under the same voltage regime. The curves in Fig. $4 \mathrm{~b}$ and $4 \mathrm{c}$ show the variation of reduction voltage for Ox and Se samples during the Co electrodeposition process, indicating two completely different behaviors. The reduction voltage in the sample whose barrier layer has been thinned by selenic acid decreases the same as the oxalic acid. 
But in the following, it has immediately increased and remained constant, whereas the reduction voltage of the sample thinned in oxalic acid decreases progressively. Based on previous works, the progressive reduction of this voltage is necessary to reach optimum and uniform electrodeposition [46]. Also, by performing the PED, the presence of the oxidation half cycle leads to an increase in the barrier layer resistivity [50]. Therefore, the reduction voltage needs to increase progressively in order to keep the electrodeposition current constant. While this progressive increase is observed in the sample thinned by oxalic acid, the reduction voltage starts to increase and remain constant in the sample thinned by selenic acid. This is indicative of non-optimized growth of nanowires in the nanopores.

By investigating magnetic properties of the two samples, it is observed that the sample thinned in oxalic acid has Hc of about 2550 Oe, whereas that of the sample thinned in selenic acid reaches 988 Oe. Moreover, the hysteresis loop of the sample thinned in oxalic acid is much more square. By investigating the results of XRD analysis [Figure 4d], the Ox sample shows diffraction peaks corresponding to hexagonal close-packed (hcp) structure of cobalt (JCPDS card no. 05-0727). It is found that the Ox sample has considerably higher hcp-(002) peak intensity compared to that of the Se sample with almost amorphous structure. In other words, the larger Hc of the sample thinned in oxalic acid results from the crystalline growth along the [002] direction as explained in previous studies [5153]. 

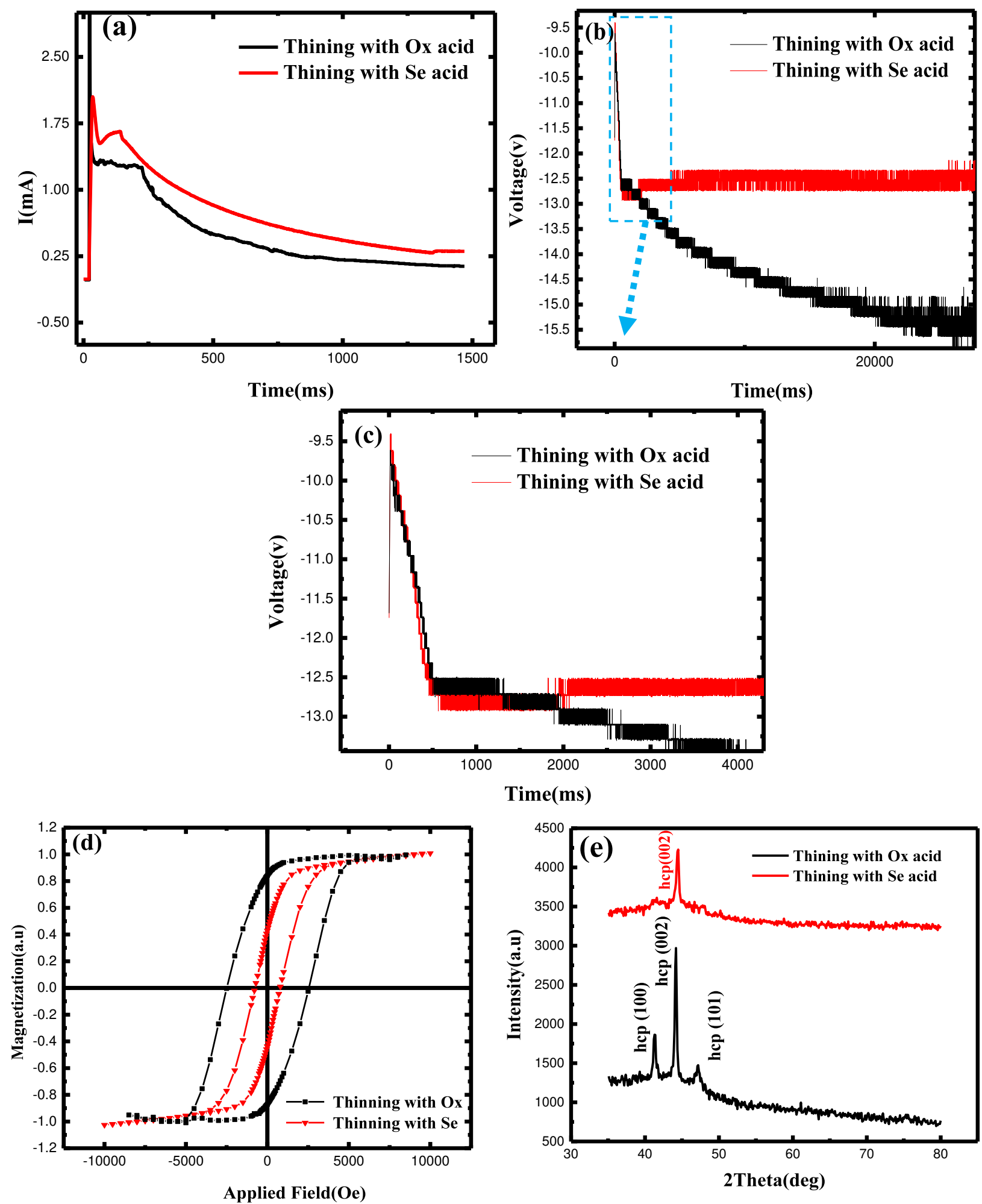

Figure 4: (a) The comparison between the initial thinning processes in oxalic $(\mathrm{Ox})$ and selenic $(\mathrm{Se})$ acids. (b) The reduction voltage-time curves for the two acids. (c) The reduction voltage-time curves for the two acids from a close view marked in part (b). (d) Normalized hysteresis loops of electrodeposited cobalt nanowires whose thinning process has been performed in oxalic and selenic acids. (e) XRD patterns of cobalt nanowires whose thinning process has been performed in oxalic and selenic acids. 


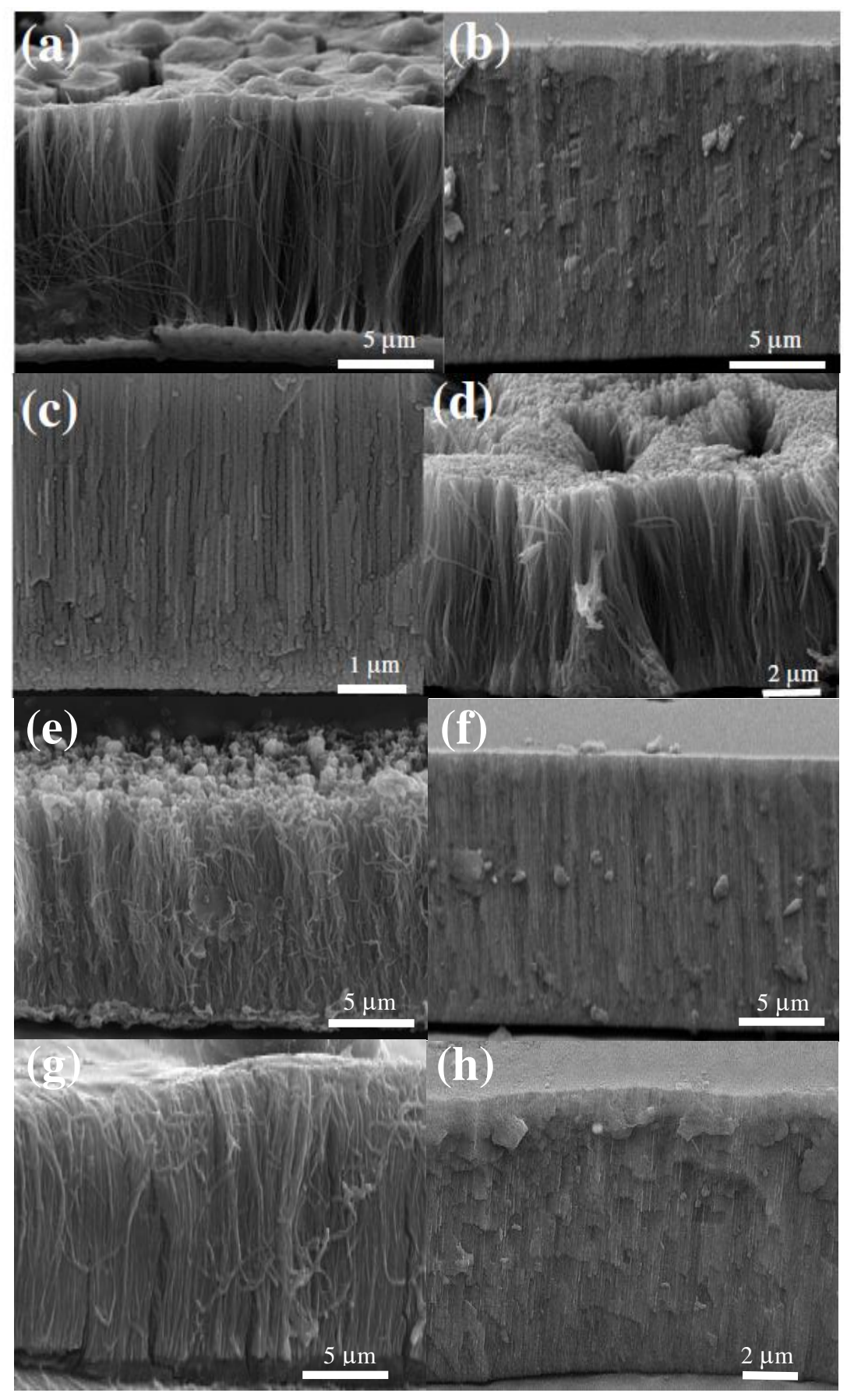

Figure 5. (a) FESEM image of free-standing Ni nanowires after their release from the APA template, (b) cross sectional FESEM image of Ni nanowires, (c) high-magnification cross sectional FESEM image of Co nanowires, (d) FESEM image of free-standing Co nanowires after their release from the APA template (e) FESEM image of free-standing $\mathrm{Zn}$ nanowires after their release from the APA template, (f) cross sectional FESEM image of Zn nanowires, (g) FESEM image of free-standing AgNi nanowires after their release from the APA template, and (h) cross sectional FESEM image of AgNi nanowires. 
Figure 5 shows FESEM image of free-standing magnetic and metallic nanowires released from the templates. As seen in these figures, it is possible to grow nanowires into the templates with small pore diameter. Magnetic and metallic nanowire images confirm the formation of small diameter nanowires. The variation of overfilling is related to the kind of deposited elements into the nanoporous templates. The overfilling charge $\mathrm{Q}_{\mathrm{rev}}$ of $\mathrm{Co}, \mathrm{Ni}, \mathrm{Zn}$ and $\mathrm{AgNi}$ nanowires is $1.1,2.56,0.8$, and $1.4 \mathrm{C}$, respectively Moreover, the respective theoretical charge $\mathrm{Q}_{\text {theo }}$ of $\mathrm{Co}, \mathrm{Ni}, \mathrm{Zn}$ and $\mathrm{AgNi}$ nanowires is found to be 1.2, 3.6, 1.2, and 1.5 C. Therefore, the length of the grown nanowires varies as the corresponding deposited charge is different. In other words, the lengths of $\mathrm{Ni}, \mathrm{Co}, \mathrm{Zn}$ and $\mathrm{AgNi}$ are measured to be 7.7, 4.9, 7 and $5.6 \mu \mathrm{m}$, respectively, according to Fig. 5.

In order to investigate the amount of pore filling, the template surface filled with nanowires was mechanically etched with a depth of $1 \mu \mathrm{m}$ below the initial surface of the template. The surface of all samples was fixed using an O-ring, eliminating the effect of the surface area $(0.35 \mathrm{~cm} 2)$ on experimental $F_{\rho}$. Figure 6 shows FESEM micrographs of the top surface of the etched samples. The obtained pore filling through these micrographs of various nanowires is displayed in Fig. 7, representing the highest pore filling of $82 \%$ for $\mathrm{AgNi}$. These experimental data is also compared with that of the theoretical method. 


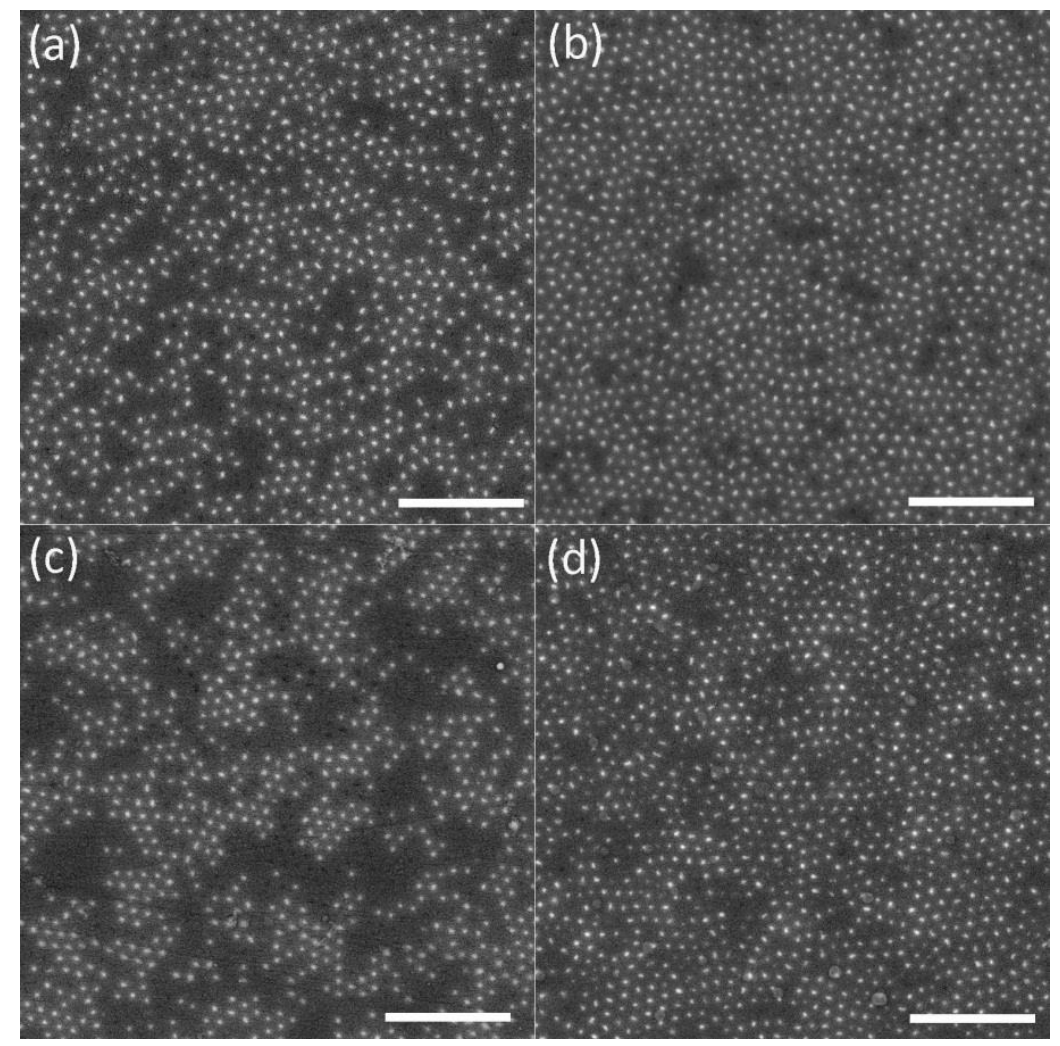

Figure 6: Top-view FESEM images of: (a) Ni, (b) Co, (c) Zn, and (d) AgNi nanowires fabricated into selenic nanoporous templates. The scale bar in all parts is $1 \mu \mathrm{m}$.

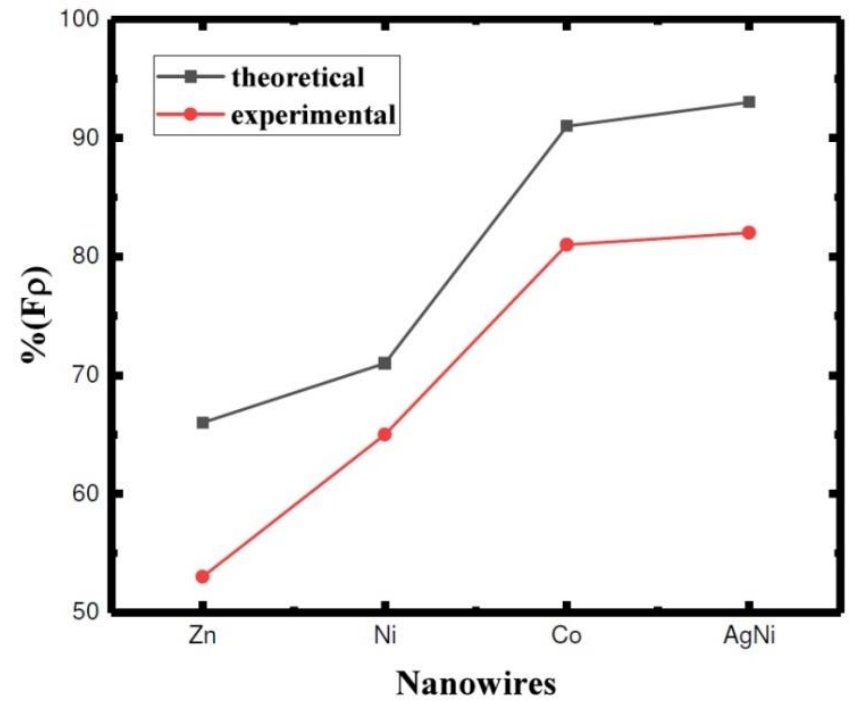

Figure 7: Experimental and theoretical pore filling percentage $\left(F_{\rho}\right)$ of selenic APA templates filled with different nanowires. 
The calculated pore filling is not the same as that of obtained by FESEM micrographs. Some nanowire may not be overfilled during the pore filling, and this is may be the reason of such differences between experimentally obtained data and theoretically calculated one. In the present study, using small pulses, short off-times and small pore diameter, an $82 \%$ pore filling was found for AgNi nanowires. The fabrication of high quality nanowires with uniform length resulted from the full filling of nanopores is important and advantageous for many applications ranging from electrochemical sensors to cathode materials for lithium storage capacity and high-density magnetic storage medium [54-56]. Notably, Ni nanowires have become important for their electrochemical energy storage, catalytic, magnetic and microwave absorbing properties [57-58] as they can be manipulated easily using an external magnetic field. Co nanowires with large shape and magnetocrystalline anisotropies can be employed in the development of high-density magnetic memories [59]. Functionalized $\mathrm{Zn}$ and calcined $\mathrm{Zn}(\mathrm{ZnO})$ nanowire arrays with high crystallinity can be valuable in dye-sensitized solar cells and gas sensors with fast response/ recovery times [60]. Ag NWs have also exhibited high chemical stability against different harsh media while also showing superior conductivity and transmittance [61]. 

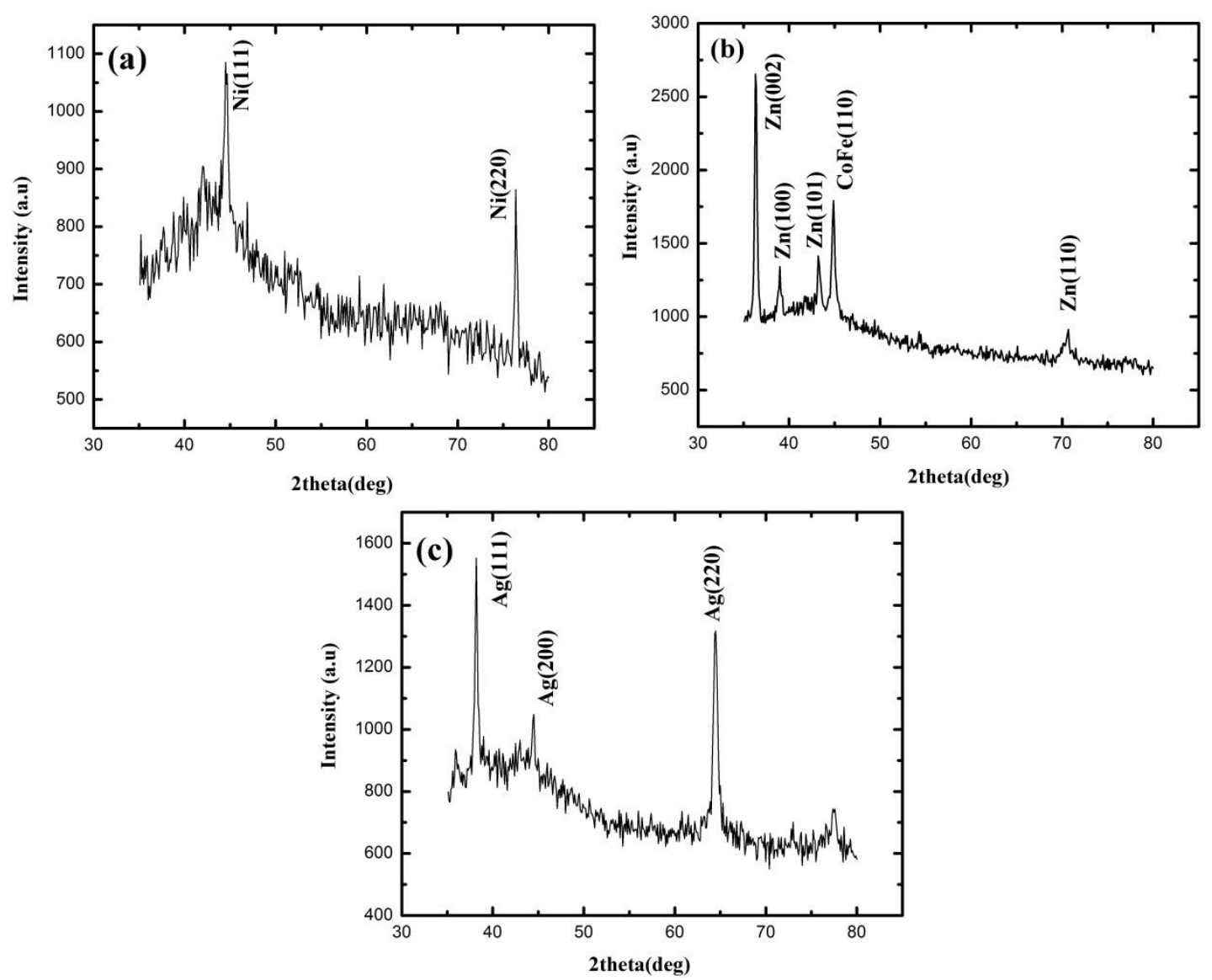

Figure 8: XRD patterns of (a) Ni, (b) Zn and (c) AgNi nanowires electrodeposited into selenic APA templates.

The crystalline characteristics of embedded magnetic and metallic nanowires into the APA templates using selenic acid were determined by XRD analysis, and the results are shown in Fig. 8. As can be seen in the XRD pattern of Figure 8a, face-centered cubic (fcc)-Ni(111) and fcc-Ni(220) peaks appear at $2 \theta=44.52^{\circ}$ and $76.40^{\circ}$ (JCPDS card no. 04-0850) for Ni nanowires, respectively. From Figure 8b, the peaks of $\mathrm{Zn}$ nanowires are indexed to the hexagonal structure of $\mathrm{Zn}$ (JCPDS card no. 87-0713). In this case, the intensity of the (002) peak is much higher than that of others, indicating that $\mathrm{Zn}$ nanowires electrodeposited in the small-diameter pores are textured along the [001] direction. It should be noted that the presence of the $\mathrm{CoFe}(110)$ at $2 \theta=44.85^{\circ}$ is related to the CoFeNi pre-plating of the branched sections of $\mathrm{Zn}$ nanowires. 
For AgNi nanowires (Fig. 8c), the diffractions peaks are attributed to fcc structure of Ag (JCPDS card no. 04-0783). The absence of Ni peaks in the XRD pattern of AgNi nanowires can be related to the additive role of $\mathrm{Ni}$ during the electrodeposition due to its low content arising from the smaller valence of $\mathrm{Ni}$ than that of $\mathrm{Ag}$ [46]. Moreover, the more positive standard reduction potential of $\mathrm{Ag}(+0.8 \mathrm{~V})$ than that of $\mathrm{Ni}(-0.25 \mathrm{~V})$ can lead to the domination of the electrodeposition of $\mathrm{Ag}$.

\section{Conclusions}

Using a two-step anodization, APA templates with small diameters were fabricated. In the first step, the anodization was performed in $0.3 \mathrm{M}$ oxalic acid at $40 \mathrm{~V}$ in order to create an ordered pattern. The second anodization step was carried out in $0.3 \mathrm{M}$ selenic acid at $45 \mathrm{~V}$ after removing the oxide layer. In this case, by investigating the diameter of nanopores, it was shown that the nanopore diameter was considerably smaller $(\sim 13 \mathrm{~nm})$. After performing the barrier layer thinning process in oxalic acid, various metals including $\mathrm{Co}, \mathrm{Ni}, \mathrm{Zn}$ and $\mathrm{AgNi}$ were electrodeposited in the nanopores in order to fabricate small-diameter nanowires. The pore filling of the nanopores was found to be relatively high $(53 \%-82 \%)$. The magnetic properties of the cobalt nanowires fabricated in the APA template showed that their coercivity can improve up to 2550 Oe.

\section{Acknowledgements}

The authors gratefully acknowledge the University of Kashan for providing the financial support of this work by Grant No. 159023/71.

\section{Compliance with Ethical Standards}

Conflict of Interest: The authors declare that they have no conflict of interest. 


\section{References}

[1]. Brinda B. Lakshmi, Charles J. Patrissi, and Charles R. Martin, Sol-Gel Template Synthesis of Semiconductor Oxide Micro- and Nanostructures, Chem. Mater. 1997, 9, 2544-2550.

[2]. E. Comini, D. Zappa, One- and two-dimensional metal oxide nanostructures for chemical sensing, Semiconductor Gas Sensors, 2020 - Elsevier.

[3] H Eren Atomic layer deposition of metal oxides on self-assembled peptide nanofiber templates for fabrication of functional nanomaterials, a thesis - 2016 repository.bilkent.edu.tr

[4] PR Reddy, KM Ajith, NK Udayashankar, Optical and mechanical studies on free standing amorphous anodic porous alumina formed in oxalic and sulphuric acid, Applied Physics A, 2018 - Springer

[5] H.Zheng, L.Zheng, M.Han and H.Qin, Preparation of Porous Silicon Templates in Two Steps of Au-Assisted Chemical Etching, Journal of Nanoscience and Nanotechnology, 16, 9746-9750, 2016.

[6] M.Alsawat, T.Altalhi, A.Santos, and D.Losic, Carbon Nanotubes-Nanoporous Anodic Alumina Composite Membranes: Influence of Template on Structural, Chemical and Transport Properties, J. Phys. Chem. C 2017, 121, 25, 13634-13644.

[7] O,Heinz1 , M,Aghajani, A.R.Greenberg and Y.Ding, Surface-patterning of polymeric membranes: fabrication and performance, Current Opinion in Chemical Engineering 2018, 20, 1-12.

[8]. L. Acosta,Francesc B.Roselló, E. Xifre-Perez, A.Santos, J.Ferré-Borrull, L. Marsal, Stacked Nanoporous Anodic Alumina Gradient-Index Filters with Tunable Multispectral Photonic Stopbands as Sensing Platforms, ACS Appl. Mater. Interfaces,(2019),11,3,3360-3371

[9]. R.Kumar, A.DixitVolume, Corrosion resists Ni, Co co-pigmented nanoporous anodized alumina as spectral selective coating structure for solar thermal applications, Journal of Alloys and Compounds,(2019),810, 151833.

[10] J. O. Carneiro, F. Machadoa, M. Pereiraa, V. Teixeiraa, M. F. Costaa, Artur Ribeirob, Artur Cavaco-Paulo, A. P. Samantilleke, The influence of the morphological characteristics of nanoporous anodic aluminium oxide (AAO) structures on capacitive touch sensor performance: a biological application, RSC Advances , (2018), 8, 37254-37266, [11]. J.Wang, R.Li, Y.Ling Xu, Sh.Lou and ShaoMin Zhou ,Enhanced thermoelectric properties of Agdoped $\mathrm{MnO} 2$ single crystal nanowires for room-temperature application, Materials Research Express, (2019), 6-7

[12]. Ono, S., Saito, M. \& Asoh, H. Self-ordering of anodic porous alumina formed in organic acid electrolytes. Electrochim. Acta 51, 827-833 (2005).

[13]. Chu, S. Z. A. et al. Large-scale fabrication of ordered nanoporous alumina films with arbitrary pore intervals by critical-potential anodization. J. Electrochem. Soc. 153, B384-B391 (2006).

[14]. Kikuchi, T.,Wachi, Y., Takahashi, T., Sakairi, M. \& Suzuki, R. O. Fabrication of a meniscus microlens array made of anodic alumina by laser irradiation and electrochemical techniques. Electrochim. Acta 94, 269-276 (2013).

[15].Li, A. P., Mu“ller, F., Birner, A., Nielsch, K. \& Go“sele, U. Polycrystalline nanopore arrays with hexagonal ordering on aluminum. J. Vac. Sci. Technol. A. 17, 1428-1431 (1999).

[16]H. Zeng, R. Skomski, L. Menon, Y. Liu, S. Bandyopadhyay, D.J. Sellmyer, Structure and magnetic properties of ferromagnetic nanowires in self-assembled arrays, 65 (2002) 1-8.

doi:10.1103/PhysRevB.65.134426. 
[17]. Fukushima, T., Fukuda, Y., Ito, G. \& Okada, M. Anodic oxidation of aluminumin aqueous solution of dicarboxylic acids. J. Surf. Fin. Soc. Jpn. 25, 447-452 (1974).

[18]. Fukushima, T., Fukuda, Y., Ito, G. \& Miyoshi, M. Anodic oxidation of aluminum at high current density in the aqueous solution of hydroxycarboxylic acids. J. Surf. Fin. Soc. Jpn. 25, 537-541 (1974). [19]. M. Norek, M. Dopierała, and W. J. St _epniowski, J. Electroanal. Chem., 750, 79 (2015).

[20]. X. Qin, J. Zhang, X. Meng, C. Deng, L. Zhang, G. Ding, H. Zeng, and X. Xu, Appl. Surf. Sci., 328,459 (2015).

[21]. T. Kao and Y. Chang, Appl. Surf. Sci., 288, 654 (2014).

[22]. S. Leung, M. Yu, Q. Lin, K. Kwon, K. Ching, L. Gu, K. Yu, and Z. Fan, Nano Lett., 12, 3682 (2012).

[23]. X. Chen, D. Yu, L. Gao, X. Zhu, Y. Song, H. Huang, L. Lu, and X. Chen, Mater. Res. Bull., 57, 116 (2014).

[24]. J. Bellemare, F. Sirois, and D. M'enard, J. Electrochem. Soc., 161, E75 (2014).

[25]. M. Yu, W. Zhang, S. Zhang, S. Zhao, F. Ai, X. Zhu, Morphology evolution of porous anodic alumina in mixed H3PO4/NH4F electrolytes, Surf. Coatings Technol. 334 (2018) 500-508. doi:10.1016/j.surfcoat.2017.12.012.

[26]. Y. Nazarkina, K. Kamnev, A. Dronov, A. Dudin, A. Pavlov, S. Gavrilov, Features of Porous Anodic Alumina Growth in Galvanostatic Regime in Selenic Acid Based Electrolyte, Electrochimica Acta 231 (2017) 327-335

[27] T.Kikuchi ,O.Nishinaga, S.Natsui, R.Suzuki, Self-Ordering Behavior of Anodic Porous Alumina via Selenic Acid Anodizing,,(2014), Electrochimica Acta, 137, 728-735

[28] O,Nishinaga, T.Kikuchi, S.Natsui \& R. Suzuki, Rapid fabrication of self-ordered porous alumina with 10-/sub-10-nm-scale nanostructures by selenic acid anodizing, SCIENTIFIC REPORTS,(2013)32748

[29] S.Akiya, T.Kikuchi, S.Natsui, and R.Suzuki, Optimum Exploration for the Self-Ordering of Anodic Porous Alumina Formed via Selenic Acid Anodizing, Journal of The Electrochemical Society, 162 (10) E244-E250 (2015)

[30]. W.L. Xu, M.J. Zheng, S. Wu, W.Z. Shen, Effects of high-temperature annealing on structural and optical properties of highly ordered porous alumina membranes, Appl. Phys. Lett. 85 (2004) 4364.

[31]. L. Cantelli, J.S. Santos, T.F. Silva, M.H. Tabacniks, A.O. Delgado-, F. Trivinho-strixino, Author's Accepted Manuscript, J. Lumin. (2018).10.015.

[32] I.S. Molchan, N.V. Gaponenko, R. Kudrawiec, J. Misiewicz, G.E. Thompson, Influence of porous anodic alumina matrix upon europium luminescence from sol-gel-derived films, Mater. Sci. Eng. B 105 (2003) 37-40.

[33]. Y. Nazarkina, S. Gavrilov, H. Terryn, M. Petrova, J. Ustarroz, Investigation of the Ordering of Porous Anodic Alumina Formed by Anodization of Aluminum in Selenic Acid, J. Electrochem. Soc. 162 (2015) E166-E172, doi:http://dx.doi.org/ 10.1149/2.0571509jes.

[34]. M. Michalska-Doma'nska, M. Norek, W.J. St epniowski, B. Budner, Fabricationof high quality anodic aluminum oxide (AAO) on low purity aluminum - acomparative study with the AAO produced on high purity aluminum,Electrochim. Acta 105 (2013) 424-432.

[35]. Sousa C, Leitao D, Proenca M, Ventura J, Pereira A and Araujo J 2014 Appl. Phys. Rev. 1031102 [36] Borissov D, Isik-Uppenkamp S and Rohwerder M 2009 J. Phys. Chem. C 1133133

[37]. V. M. Prida, V. Vega, J. García, L. Iglesias, B. Hernando, I. Minguez-Bacho, 1- Electrochemical methods for template-assisted synthesis of nanostructured materials A2 - Vázquez, Manuel, Magnetic Nano- and Microwires, Woodhead Publishing 2015, pp. 3-39.

[38] C. Sousa, D. Leitao, M. Proenca, J. Ventura, A. Pereira, J. Araujo, Nanoporous alumina as templates for multifunctional applications, Applied Physics Reviews, 1 (2014) 031102 
[39] V. M. Prida, J. García, B. Hernando, C. Bran, L.G. Vivas, M. Vázquez, 2- Electrochemical synthesis of magnetic nanowires with controlled geometry and magnetic anisotropy, Magnetic Nanoand Microwires, Woodhead Publishing (2015), pp. 41-104.

[40] C Bran, E M Palmero, Zi-An Li , R P del Real, M Spasova, M Farle and M Vázquez, Correlation between structure and magnetic properties in CoxFe100-x nanowires: the roles of composition and wire diameter,2015, J. Phys. D: Appl. Phys, 48 , 145304 (7pp)

[41] Kashi M A and Ramazani A ,2005 J. Phys. D: Appl. Phys. 382396

[42]. K. Nielsch, F. Müller, A.-P. Li, U. Gösele, Uniform nickel deposition intoordered alumina pores by pulsed electrodeposition, Adv. Mater. 12 (2000)582-586.

[43]. Sousa C, Leitao D, Proenca M, Apolinario A, Correia J, Ventura J and Araujo J 2011 Nanotechnology 22315602

[44]. H. Zeng, R. Skomski, L. Menon, Y. Liu, S. Bandyopadhyay, and D. J. Sellmyer, Structure and magnetic properties of ferromagnetic nanowires in self-assembled arrays,(2002), J. Phys.Review B, 65, 134426

[45] S.F.A.A. Ramazani, M.A. Kashi, A.H. Montazer, The effect of barrier layer conditions on the electrodeposition efficiency and magnetic properties of $\mathrm{Fe}$ nanowire arrays, Appl. Phys. A. 0 (2018), 124:379.

[46] M. Arefpour, M.A. Kashi, A. Ramazani, A.H. Montazer, Electrochemical pore fi lling strategy for controlled growth of magnetic and metallic nanowire arrays with large area uniformity, Nanotechnology. 27 (2016) 275605 (12pp)

[47] I. U. Schuchert, M. E. Toimil Molares, D. Dobrev, J. Vetter, R. Neumann, and M. Martin, Electrochemical Copper Deposition in Etched Ion Track Membranes, Journal of The Electrochemical Society, 150 (4) C189-C194 (2003)

[48] Nielsch K, Choi J, Schwirn K, Wehrspohn R B and Gosele U

2002 Nano Lett. 2677

[49] W. Lee, S.J. Park, Porous Anodic aluminum oxide: anodization and templated synthesis of functional nanostructures, Chem. Rev. 114 (15) (2014) 7487-7556.

[50] M. AlmasiKashi, A.Ramazani, M.Ghaffari, V.B.Isfahani, Journal of Crystal Growth 311(2009)4581-4586

[51] N. Zafar, S. Shamaila, R. Sharif, H. Wali, S. Naseem, S. Riaz, M. Khaleeq-ur-Rahman, Effects of $\mathrm{pH}$ on the crystallographic structure and magnetic properties of electrodeposited cobalt nanowires. Journal of Magnetism and Magnetic Materials, 377 (2015), 215-219.

[52] A. H. Montazer, A. Ramazani, M. Almasi Kashi, J. Zavašnik. "Angular-dependent magnetism in Co (001) single-crystal nanowires: capturing the vortex nucleation fields." Journal of Materials Chemistry C 4, no. 45 (2016): 10664-10674

[53] L. G. Vivas, J. Escrig, D. G. Trabada, G. A. Badini-Confalonieri, M. Vázquez. "Magnetic anisotropy in ordered textured Co nanowires." Applied Physics Letters 100, no. 25 (2012): 252405

[54] C.A.Ross, Patterned magnetic recording media, Annu. Rev. Mater.Res.(2001) 31-

203

[55] L.Piraux, K.Renard, R.Guillemet, S.Mátéfi-Tempfli, M.Mátéfi-Tempfli ,V.A.Antohe ,S.Fusil,

K.Bouzehouane and V.Cros, Template-grown NiFe/Cu/NiFe nanowires for spin transfer devices,(2007)

Nano Lett. 72563

[56] D.Su, H.S.Kim, W.S.Kim and G.Wang, Mesoporous Nickel Oxide Nanowires:

Hydrothermal Synthesis, Characterisation and Applications for Lithium-Ion Batteries

and Supercapacitors with Superior Performance, (2012) Chem. Eur. J.18 8224

[57] C. Frantz, C. Vichery, J. Zechner, D. Frey, G. Bürki, H. Cebeci, J. Michler, L. Philippe,

Pulse electrodeposition of adherent nickel coatings onto anodized aluminium surfaces,

Applied Surface Science, 330 (2015) 39-47. 31 
[58] M. Safarzadeh, A. Arab, S. Boutorabi, The effects of anodizing condition and post treatment on the growth of nickel nanowires using anodic aluminum oxide, Iran. J.

Mater. Sci. Eng, 7 (2010) 12-18. 32

[59] Y.P.Ivanov, A,Chuvilin, S.Lopatin, J.Kosel ,Modulated Magnetic Nanowires for Controlling Domain Wall Motion: Toward 3D Magnetic Memories, ACS Nano 2016, 10, 5, 5326-5332.

[60] S.Rackauskas, N.Barbero, C.Barolo and G.Viscardi, $\mathrm{ZnO}$ nanowires for dye sensitized solar cells, Publication by Intech, 2017

[61] L Adler-Abramovich, M Reches, VL Sedman, S Allen, Thermal and chemical stability of diphenylalanine peptide nanotubes: implications for nanotechnological applications, Langmuir, 2006 ACS Publications 


\section{Figures}

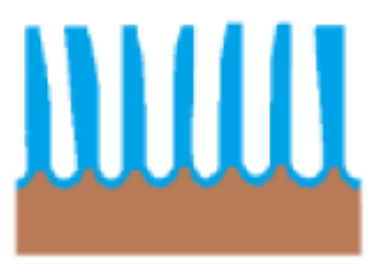

First anodization (oxalic acid)

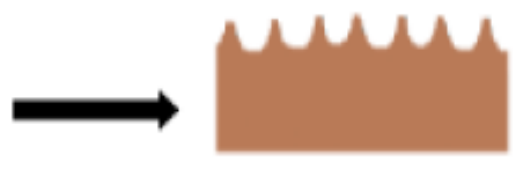

Oxide dissolution

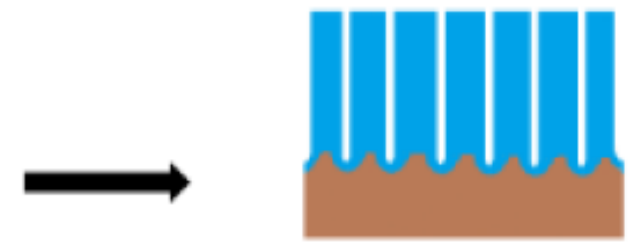

Second anodization (selenic acid)

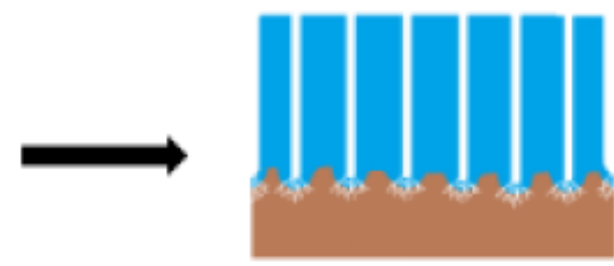

Barrier layer thinning

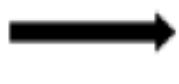

Electrodeposition

Figure 1

Schematic diagram of various steps of nanowire preparation. 


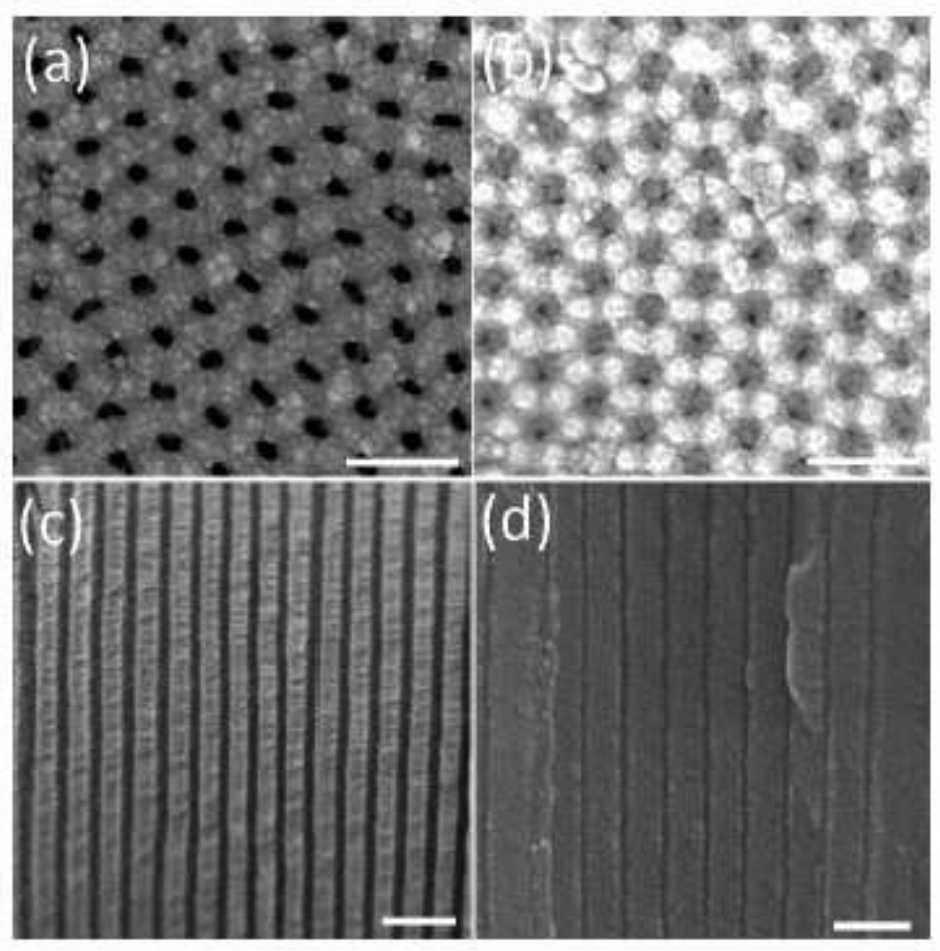

(e)

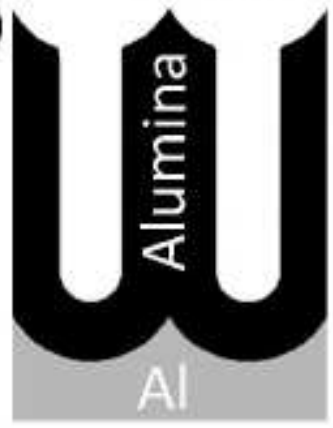

(f)

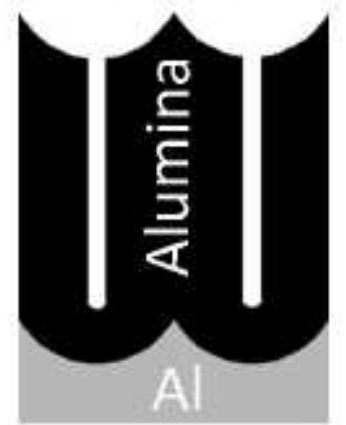

Figure 2

FESEM images of: (a) nanopores after the second anodization with oxalic acid, (b) nanopores after the second anodization with selenic acid, c) cross-section of the nanoporous template after the second anodization with oxalic acid, and d) cross-section of the nanoporous template after the second anodization with selenic acid. Schematic view of nanopores grown in alumina templates by using: (e) oxalic acid (larger diameter) and (f) selenic acid (smaller diameter). The scale bar in all parts is $200 \mathrm{~nm}$. 


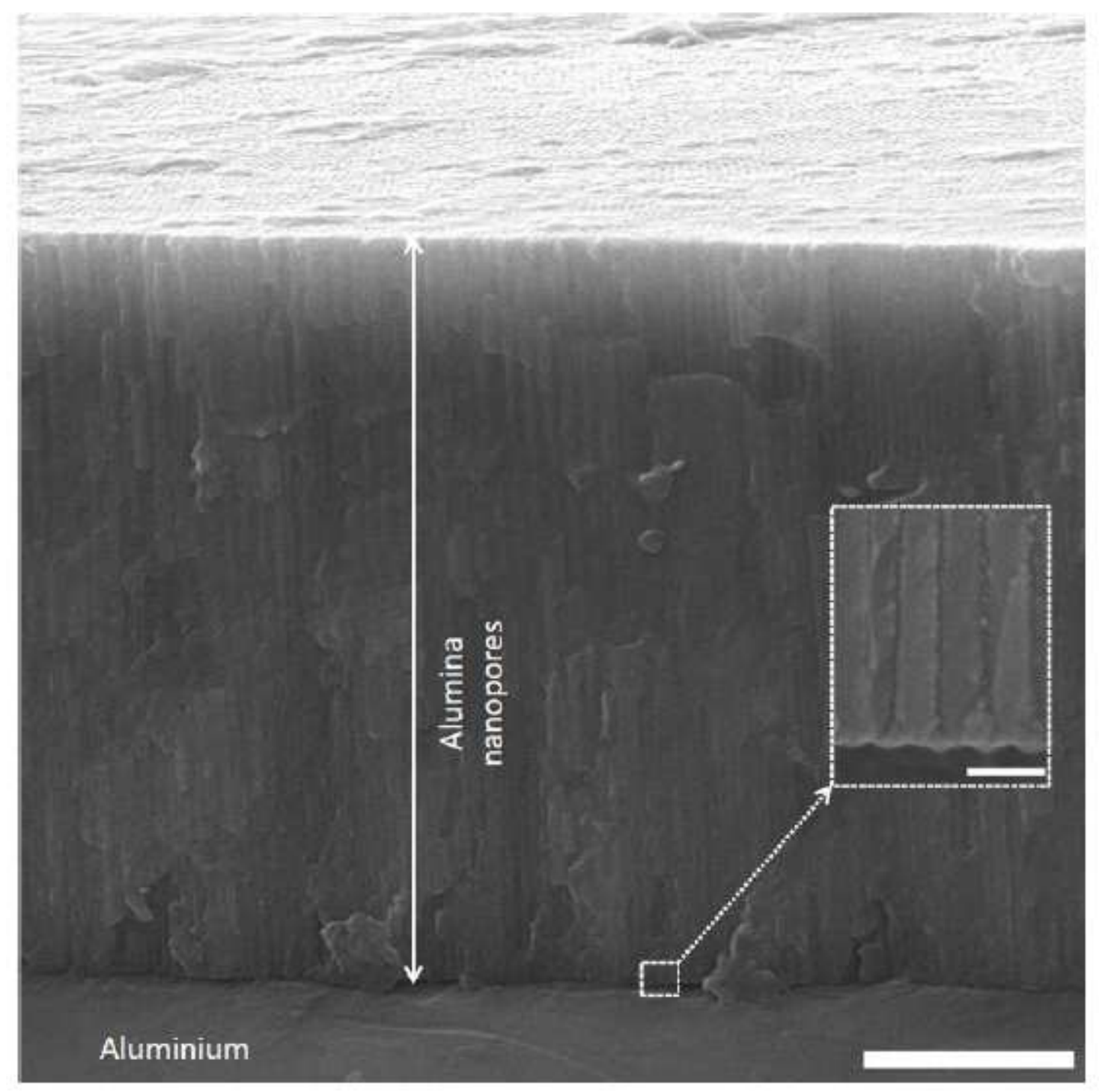

\section{Figure 3}

Cross-sectional FESEM image of alumina nanopores grown in selenic acid (the scale bar is $2 \mu \mathrm{m}$ ). The inset shows the barrier layer of the nanopores (the scale bar is $200 \mathrm{~nm}$ ). 


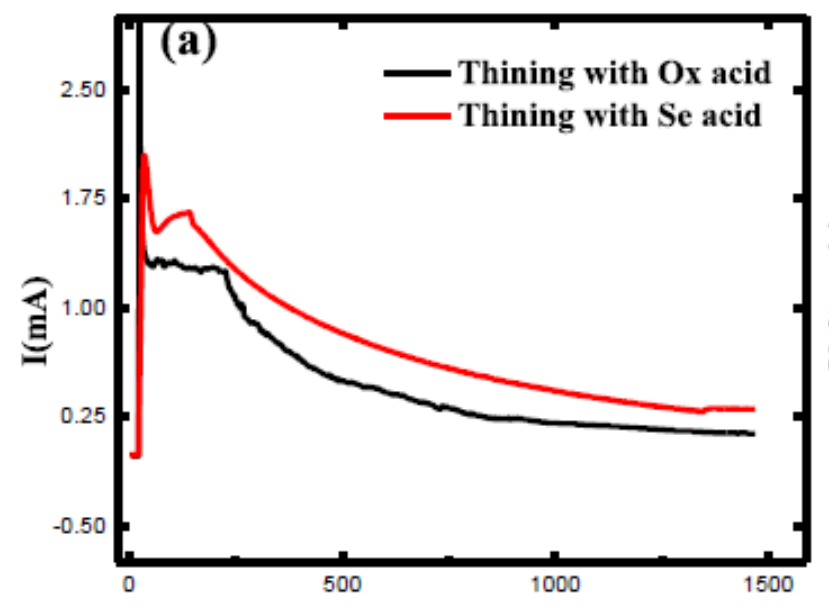

Time(ms)

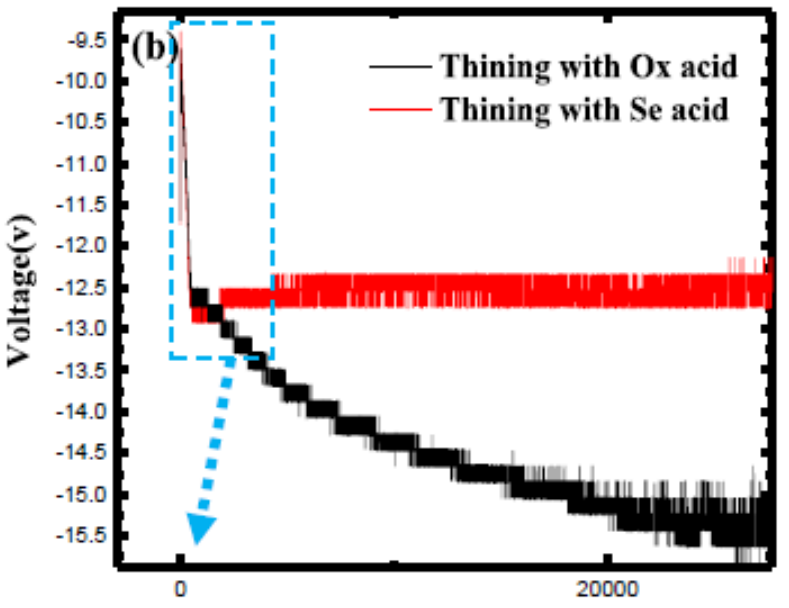

Time(ms)

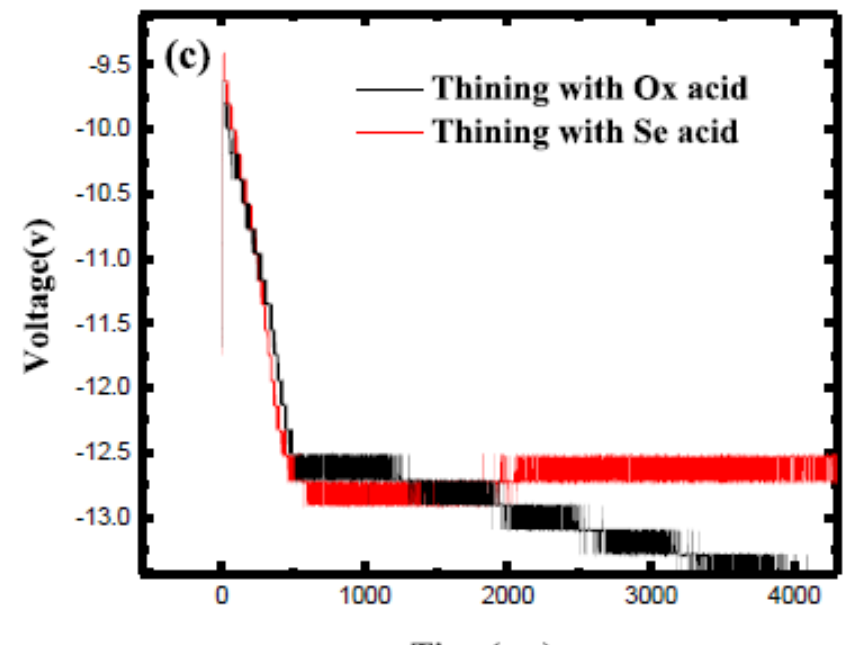

Time(ms)
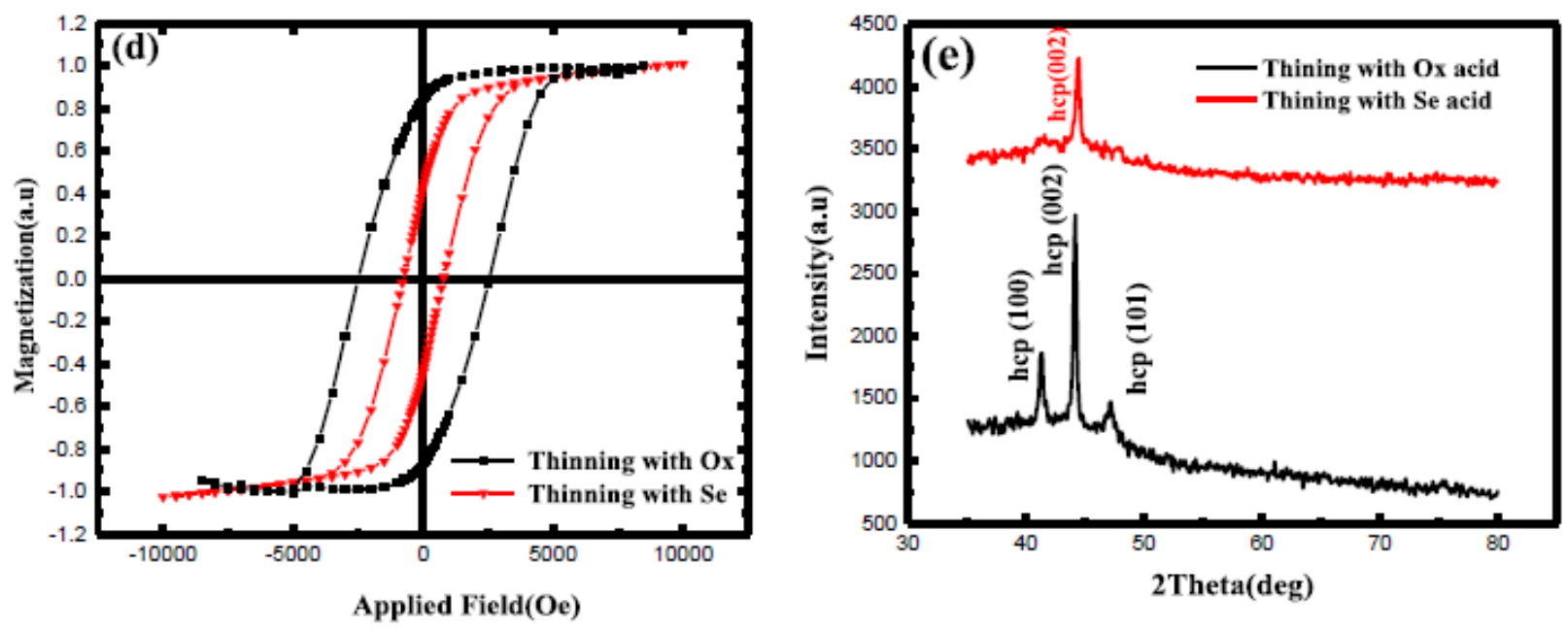

Figure 4

(a) The comparison between the initial thinning processes in oxalic (Ox) and selenic (Se) acids. (b) The reduction voltage-time curves for the two acids. (c) The reduction voltage-time curves for the two acids from a close view marked in part (b). (d) Normalized hysteresis loops of electrodeposited cobalt nanowires whose thinning process has been performed in oxalic and selenic acids. (e) XRD patterns of cobalt nanowires whose thinning process has been performed in oxalic and selenic acids. 


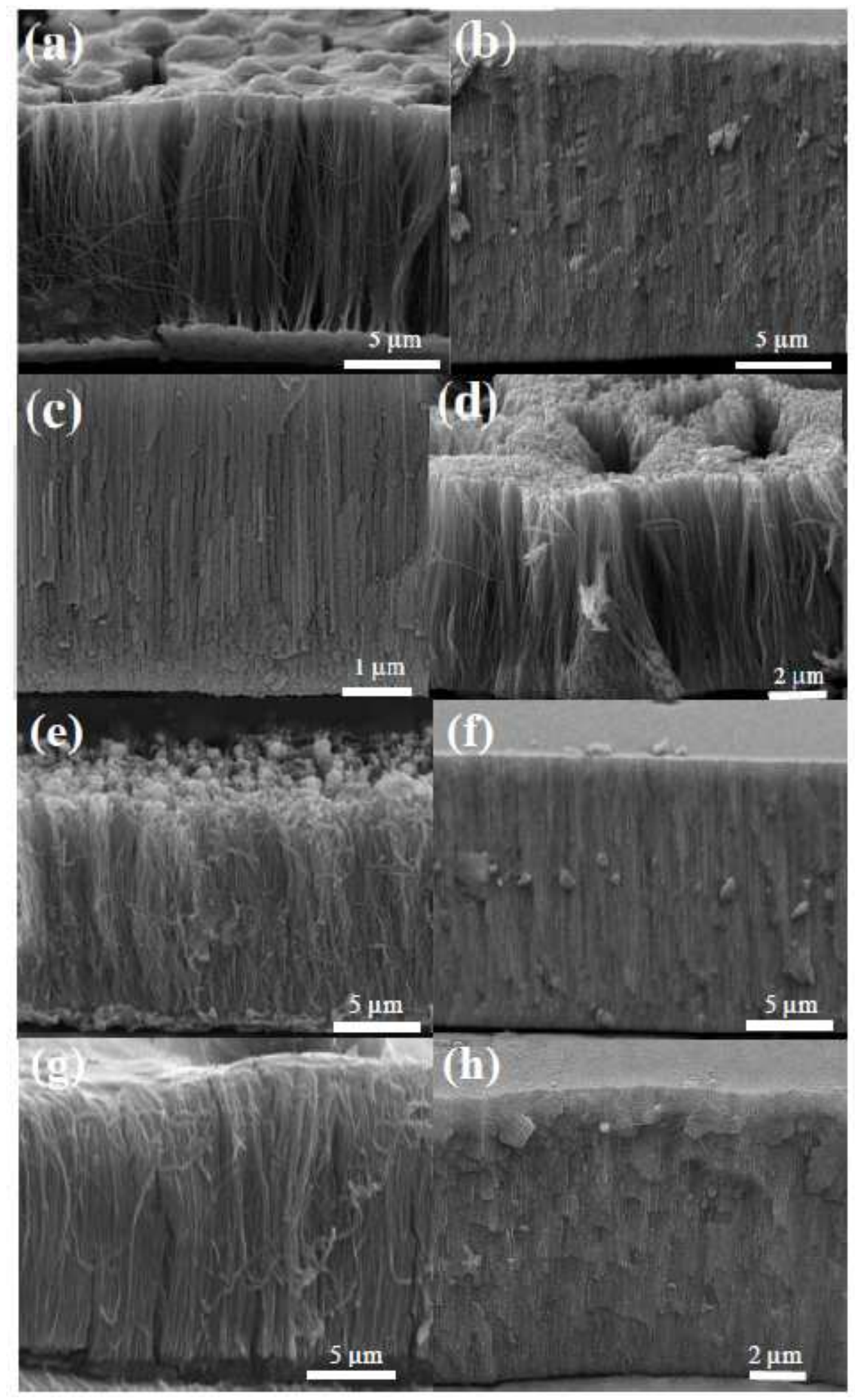

Figure 5

(a) FESEM image of free-standing Ni nanowires after their release from the APA template, (b) cross sectional FESEM image of Ni nanowires, (c) high-magnification cross sectional FESEM image of Co nanowires, (d) FESEM image of free-standing Co nanowires after their release from the APA template (e) FESEM image of free-standing $\mathrm{Zn}$ nanowires after their release from the APA template, (f) cross sectional 
FESEM image of Zn nanowires, (g) FESEM image of free-standing AgNi nanowires after their release from the APA template, and (h) cross sectional FESEM image of AgNi nanowires.

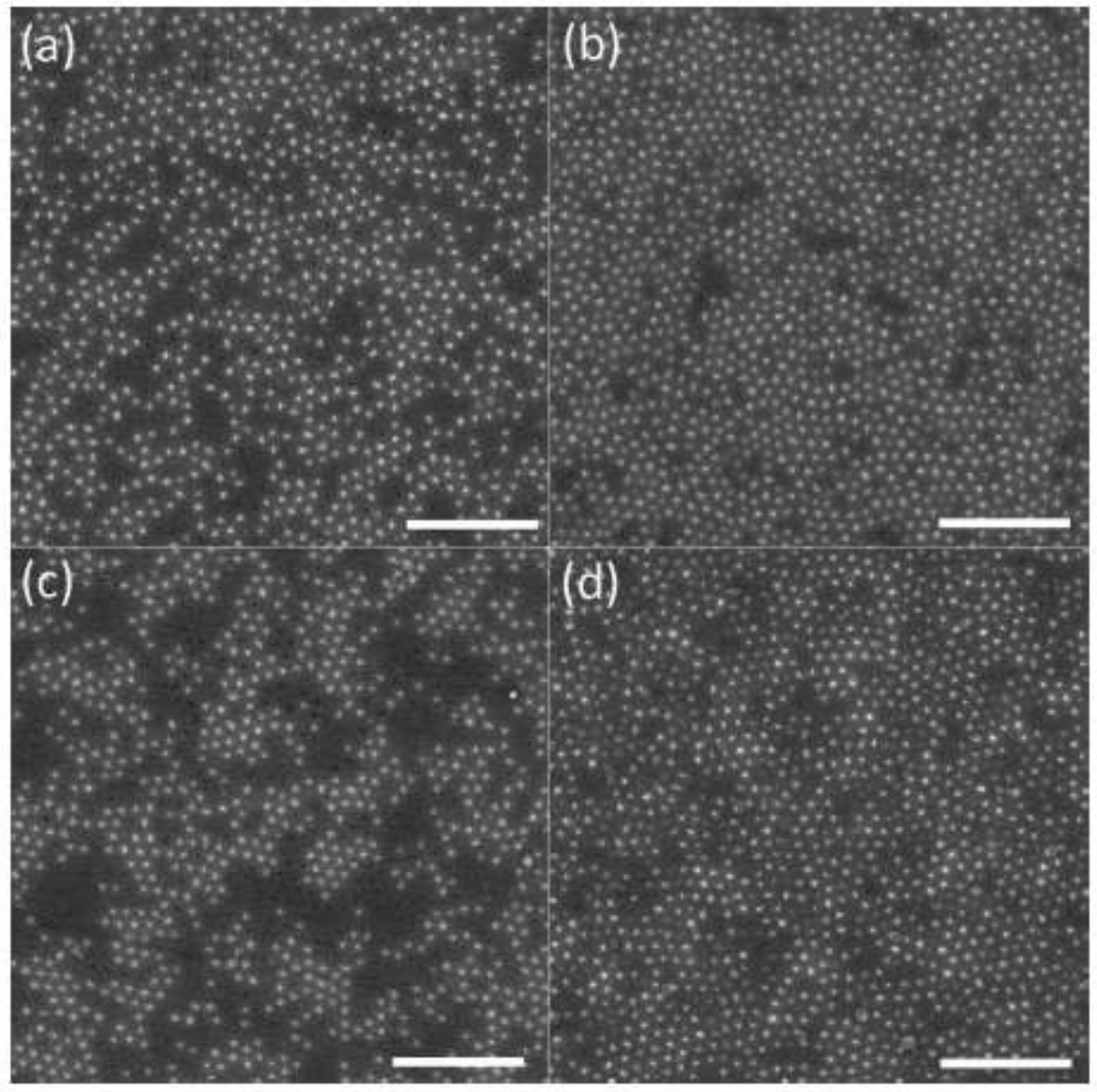

\section{Figure 6}

Top-view FESEM images of: (a) Ni, (b) Co, (c) Zn, and (d) AgNi nanowires fabricated into selenic nanoporous templates. The scale bar in all parts is $1 \mu \mathrm{m}$.

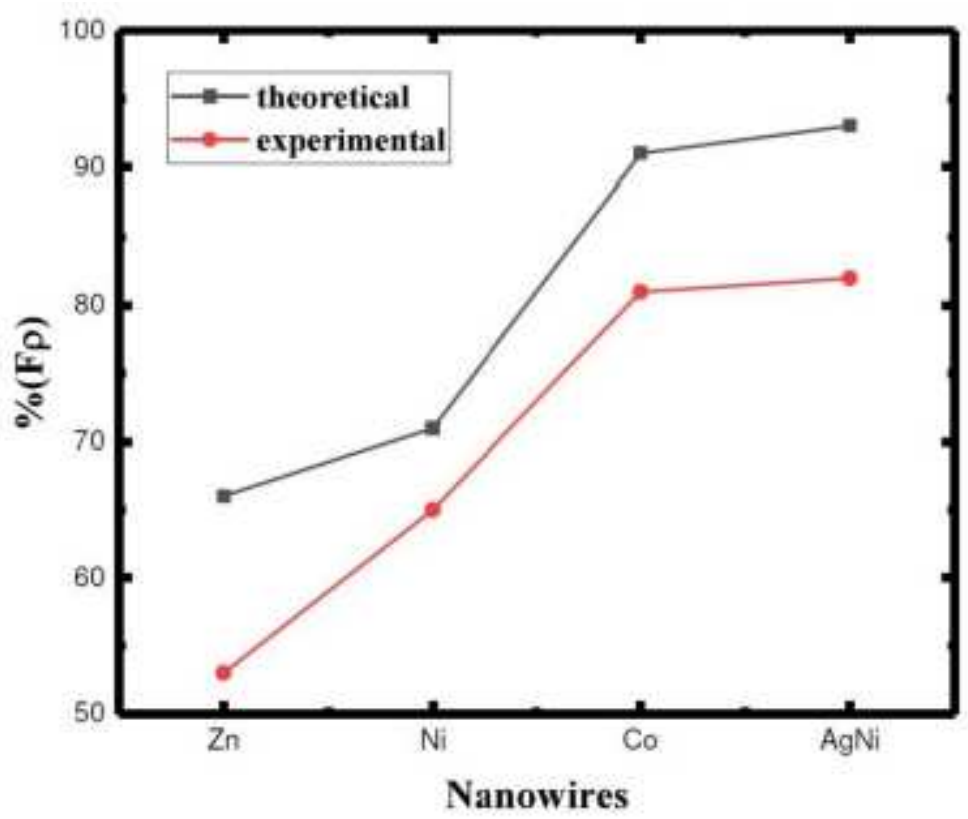


Figure 7

Experimental and theoretical pore filling percentage (怄) of selenic APA templates filled with different nanowires
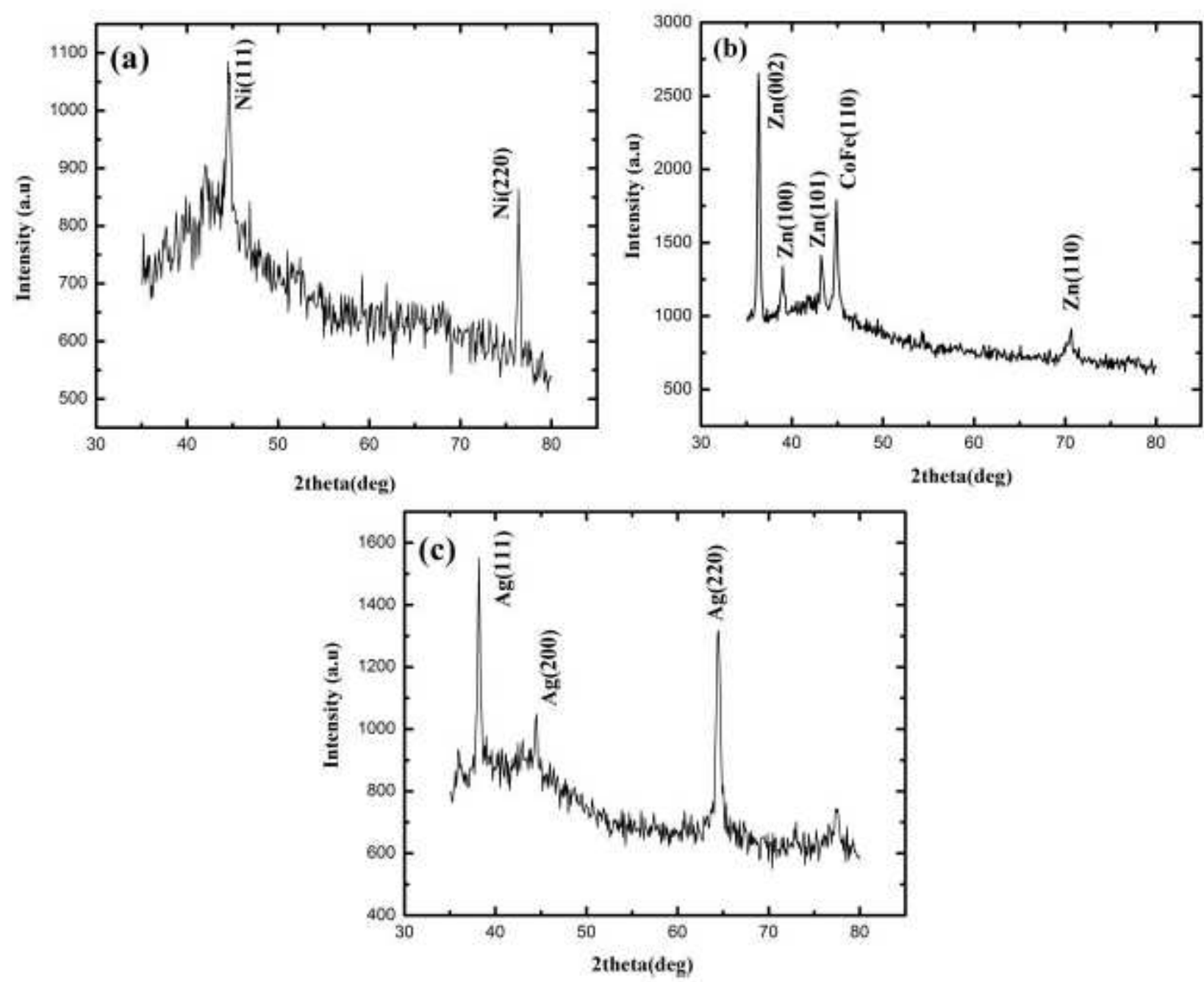

Figure 8

XRD patterns of (a) Ni, (b) Zn and (c) AgNi nanowires electrodeposited into selenic APA templates.

\section{Supplementary Files}

This is a list of supplementary files associated with this preprint. Click to download.

- GA.jpg 